\title{
CMIP5 CLIMATE MODEL ANALYSES Climate Extremes in the United States
}

by Donald Wuebbles, Gerald Meehl, Katharine Hayhoe, Thomas R. Karl, Kenneth Kunkel, Benjamin Santer, Michael Wehner, Brian Colle, Erich M. Fischer, Rong Fu, Alex Goodman, Emily Janssen, Viatcheslav Kharin, Huikyo Lee, Wenhong Li, Lindsey N. Long,

Seth C. Olsen, Zaitao Pan, Anjı Seth, Justin Sheffield, and Liqiang Sun

\section{CMIP5 model simulations of historical and projected}

climate extremes in the United States are assessed.

$\mathrm{T}$ his is the fourth in a series of BAMS articles on climate extremes in the United States (U.S.). These papers are based on workshops where leading scientists in the field came together to determine how best to assess the state of the science in understanding long-term climate variability and changes in various types of extreme events affecting the United States. The first workshop focused on severe local storms (Kunkel et al. 2013). The second

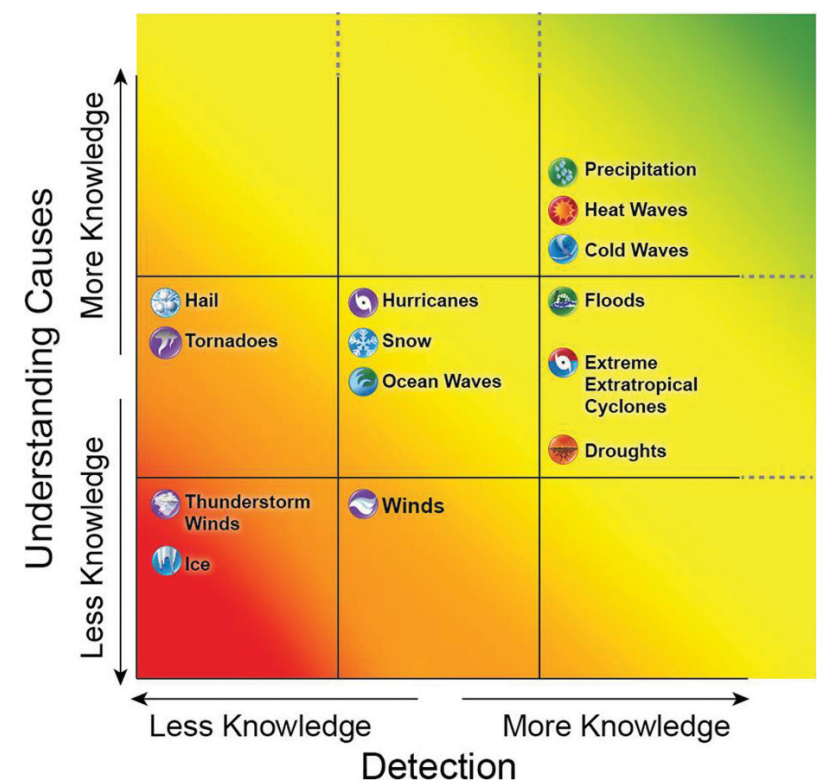

workshop focused on the larger-scale phenomena of heat waves, cold waves, floods, and drought (Peterson et al. 2013). The third workshop examined the current understanding of coastal issues, including observed trends in winds, waves, and extratropical storms (Vose et al. 2014). One of the outcomes of those workshops and the resulting papers was the collective assessment of the state of knowledge regarding changes in various climate extremes (Fig. 1). The

FIG. I. The collective assessment of the state of knowledge regarding changes in various extreme events from the three earlier climate extremes workshops (Kunkel et al. 2013; Peterson et al. 2013; Vose et al. 2014). This graphic is based on the assumption that detection and attribution of changes in extremes depend on scientists' physical understanding of the factors that cause a particular extreme, as well as on factors that may cause the intensity or frequency of that extreme to change over time and the quality and quantity of the data. The $x$ axis refers to the adequacy of data to detect trends while the $y$ axis refers to the scientific understanding of what drives those trends-that is, how well the physical processes are understood, and thus how the extremes are expected to change in the future. For each axis, the type of event is assigned to one of three categories of knowledge (from less to more). The dashed lines on the right side and top of the graph imply that the knowledge about the phenomena is not complete. 
findings in these workshops also strongly correlate with the global findings in the recent Intergovernmental Panel on Climate Change (IPCC) special report on extreme events (Field et al. 2012; often termed the SREX report).

The previous three workshops focused on the state of current knowledge regarding observed trends in, and drivers of, extreme events. The fourth workshop, the World Climate Research Programme (WCRP) Workshop on phase 5 of the Coupled Model Intercomparison Project (CMIP5) Climate Model Analyses held in March 2012, focused on the ability of the latest generation of climate models to capture observed trends and features of the physical climate system. Our intent in this paper is to assess the latest scientific understanding of CMIP5 model ability to simulate observed and future trends in climate extremes; it is not our intention to provide a complete summary of the entire body of work presented at the WCRP workshop, nor are we able to summarize results from other climate model experiments external to the CMIP5 experiment. For consistency with the previous three workshops, this assessment is limited to those papers presented at that workshop that specifically focused on climate and extreme events relevant to the U.S. With its geographic focus on the U.S., this paper also contributes the ongoing U.S. National Climate Assessment (www.globalchange .gov/what-we-do/assessment).

CMIP EXPERIMENTS. With participation from over 20 modeling groups and more than 40 global models, CMIP5 represents the latest and most ambitious coordinated international climate model intercomparison exercise to date (Taylor et al. 2012). CMIP5 includes a wide range of experiments addressing cloud feedbacks, carbon cycle feedbacks, and paleoclimate. Here, we focus on simulations of the twentieth century based on natural and anthropogenic forcings and the twenty-first century (with extensions to 2300) based on four new scenarios called representative concentration pathways (RCPs; Meehl and Hibbard 2007; Hibbard et al. 2007; Moss et al. 2010; van Vuuren et al. 2011).

Phase 3 of the Coupled Model Intercomparison Project (CMIP3) was the first coordinated international set of climate model experiments to include twentieth- and twenty-first-century experiments (Meehl et al. 2005, 2007). The IPCC's third and fourth Assessment Reports (TAR and AR4) were largely based on CMIP3 simulations. Given the increases in spatial resolution and other improvements in climate modeling capabilities over the last decade since the CMIP3 simulations were completed, CMIP5 provides a unique opportunity to assess scientific understanding of climate variability and change over a range of historical and future conditions.

Despite increases in model resolution and complexity, projected patterns and magnitudes of future temperature and precipitation changes are not substantially different from CMIP3 to CMIP5, both globally and over North America, when differences in forcings are accounted for. Estimates of climate sensitivity (Andrews et al. 2012) and hence the range in future projections due to uncertainty in climate sensitivity is also largely unchanged (Knutti and Sedláček 2012).

To put the new RCP scenarios and CMIP5 models in context, Fig. 2 compares historical simulated and projected future changes in annual-mean surface air temperature averaged over the contiguous United States (CONUS) for the period 1900-2100 as simulated by the CMIP3 model ensemble using the Special Report on Emissions Scenarios (SRES) scenarios (Nakicenovic and Swart 2000) and CMIP5 model ensemble using the RCP scenarios. An ensemble average
AfFiliations: Wuebbles, Goodman, Janssen, Lee, ANd OlsenUniversity of Illinois at Urbana-Champaign, Urbana, Illinois; MeEHL-National Center for Atmospheric Research, Boulder, Colorado; HAYHOE-Texas Tech University, Lubbock, Texas; KARLNOAA/National Climatic Data Center, Asheville, North Carolina; KUNKEL AND SUN-NOAA/Cooperative Institute for Climate and Satellites, Asheville, North Carolina; SANTER-Lawrence Livermore National Laboratory, Livermore, California; WEHNER-Lawrence Berkeley National Laboratory, Berkeley, California; CoLle-Stony Brook University, Stony Brook, New York; FISCHER-ETH, Zurich, Switzerland; Fu-The University of Texas at Austin, Austin, Texas; LI-Duke University, Durham, North Carolina; KHARINCanadian Centre for Climate Modelling and Analysis, Victoria, British Columbia, Canada; LONG—NCEP/NWS/NOAA, and Wyle
Laboratories, Camp Springs, Maryland; PAN-Saint Louis University, St. Louis, Missouri; SETH-University of Connecticut, Storrs, Connecticut; SHeffIeLD-Princeton University, Princeton, New Jersey CORRESPONDING AUTHOR: Donald J. Wuebbles, Department of Atmospheric Sciences, University of Illinois, Urbana, IL 6180I E-mail:wuebbles@illinois.edu

The abstract for this article can be found in this issue, following the table of contents.

DOI:10.1175/BAMS-D-12-00172.1

A supplement to this article is available online (I0.II75/BAMS-D-I2-00172.2)

In final form 14 June 2013

C일 American Meteorological Society 
for each model based on all available realizations was calculated prior to the calculation of the equally weighted multimodel averages. At the lower end of the range, the stabilization scenario RCP2.6 reaches its peak change of $2^{\circ} \mathrm{C}$ above the 1901-60 average around the middle of this century. The higher scenario, RCP8.5, drives end-of-century temperature increases in excess of $6^{\circ} \mathrm{C}$, significantly warmer than those projected by SRES A2. SRES B1 and RCP 4.5 produce similar but not identical responses over the U.S. at the end of the century, as do SRES A1B and RCP6.0.

The CONUS mean change is similar to that projected for the global mean (land and ocean). An assessment of the total uncertainty for the CONUS projections would be almost certainly larger (Knutti and Sedláček 2012) but is not as straightforward to estimate as previously done for global-mean temperature change in the IPCC AR4 using simple climate models, as there is no way to estimate regional climate sensitivities from those models.

Here, we focus on CMIP5-simulated historical and projected future trends in extreme temperature, heavy precipitation, drought, and extratropical cyclones. The CMIP5 models used in the various analyses are listed in Table S1 (i.e., more information can be found online at http://dx.doi.org//0.1/75 /BAMS-D-12-00172.2).

EXTREME TEMPERATURE. Observations dating back to 1900 show that the temperatures in the twenty-first century have the largest spatial extent of record breaking and much above normal mean monthly maximum and minimum temperatures (Karl et al. 2012). However, the frequency of intense short-duration hot spells is still second to the levels achieved during the hot and dry 1930s (Peterson et al. 2013; hot spells were defined as 4-day periods whose mean temperatures exceeded a threshold for a 1-in5 -yr recurrence). There is also a highly significant decrease in record-breaking cold months including decreases in short-duration cold spells from a maximum in the 1980s to the lowest levels on record in the twenty-first century (Peterson et al. 2013; cold spells were defined as 4 -day periods whose mean temperatures were below a threshold for a 1-in-5-yr recurrence). CMIP5-simulated changes in extreme high and low monthly temperatures (defined here as the single hottest and coldest months in a $30-\mathrm{yr}$ period) show that these are expected to grow over time. Projected multimodel mean increases in the temperature of the hottest and coldest months of the year are large across the U.S. under the RCP8.5 scenario (see Fig. ES1 in the supplementary materials). For the contiguous U.S., cold spell temperature increases range from around $3^{\circ} \mathrm{C}$ in Florida to more than $8^{\circ} \mathrm{C}$ in the north-central U.S. for $2071-99$ compared to 1971-2000. Hot spell temperature increases range from around $5^{\circ} \mathrm{C}$ in far southern areas and along the west coast to more than $7^{\circ} \mathrm{C}$ in parts of the Midwest and northern Rockies. Temperature increases in Alaska (Hawaii) are similar (slightly lower) for the hottest month and greater (lower) for Alaska (Hawaii) for the coldest month.

Using metrics for the combined temperaturehumidity health effects [e.g., heat index (Steadman 1979), temperature-humidity index (HUMIDEX; Masterson and Richardson 1979), and wet bulb globe temperature (Sherwood and Huber 2010)], both CMIP5 and earlier model simulations consistently project increasing levels of heat stress across the U.S. (e.g., Delworth et al. 1999; Sherwood and Huber 2010; Willett and Sherwood 2012; Fischer et al. 2012). While the projected twenty-first-century changes for the temperature component of heat stress vary substantially across CMIP5 models, there is a clear joint behavior; models that show greater warming also show greater reductions in relative humidity 
over the continental U.S. This implies that projected increases in combined temperature-humidity measures are substantially more robust than from the two contributing variables independently (Fischer and Knutti 2013). Although most models project somewhat lower relative humidity on the hottest days, the combined effect of temperature and humidity changes is substantial increases in heat stress.

The 20-yr return value of the annual maximum or minimum daily temperature is one measure of changes in rare temperature extremes. In a changing climate, this metric is interpreted as a temperature that has a $5 \%$ chance of being exceeded by an annual extreme in any given year. Figure 3 (bottom) shows the projected change in the 20 -yr return value of the annual maximum daily surface air temperature over North America at the end of this century (2081-2100) relative to the recent past (1986-2005) for the higher and lower emission RCP scenarios (Kharin et al. 2013). Under the lower RCP2.6 scenario, current annual maximum temperature extreme values are projected to occur between 4 and 10 times more frequently than at the beginning of the twentyfirst century. Under the higher RCP8.5 scenario, current annual maximum extremes are projected to occur every year over the entire continent except for parts of Alaska. Figure 3 (top) shows the same for annual minimum daily surface air temperature, which is considerably larger than for the hot extreme temperatures. Under the RCP2.6 scenario, annual

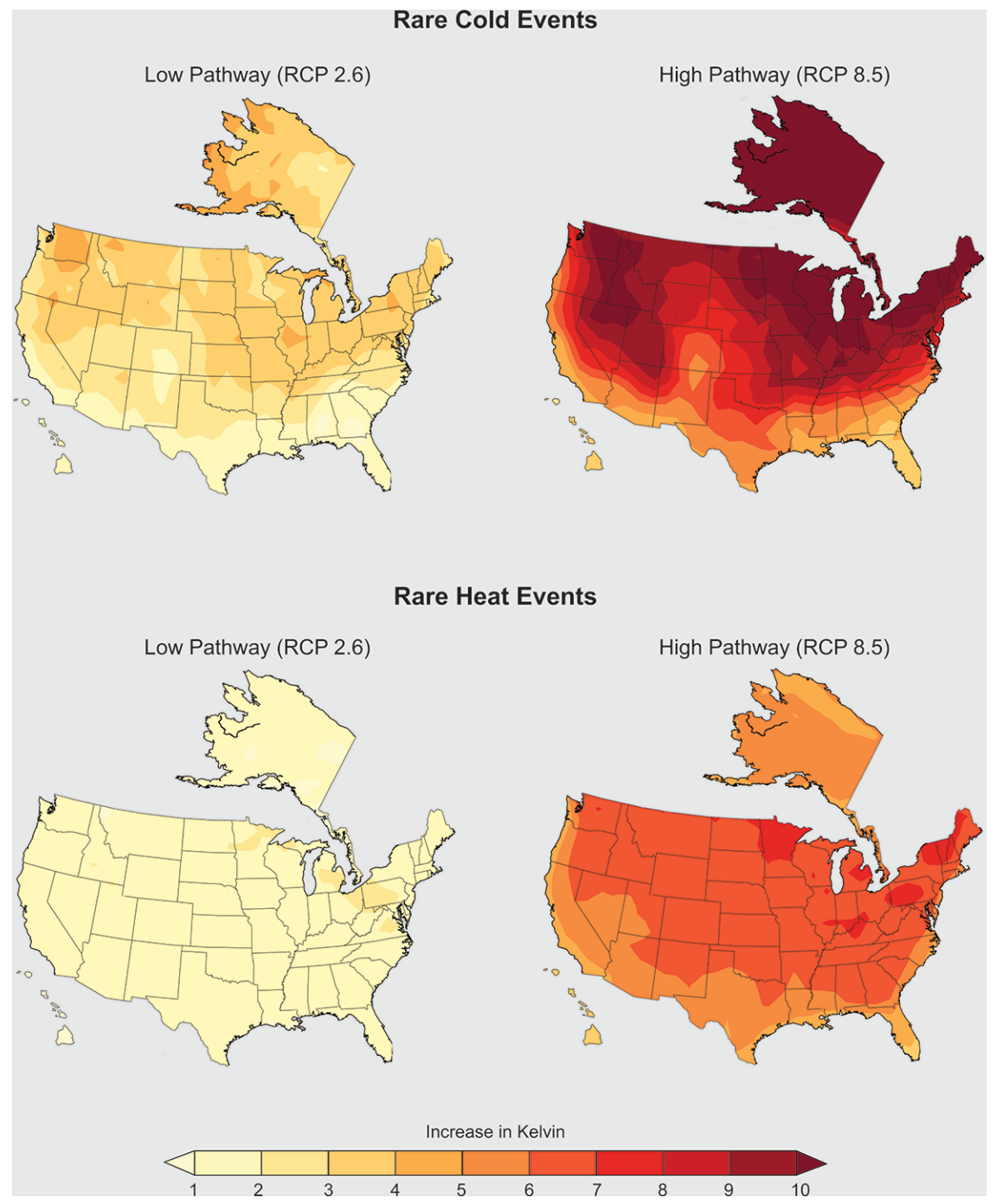

FIG. 3. (top) Projected change $\left({ }^{\circ} \mathrm{C}\right)$ in the 20 -yr return value of annual minimum daily surface air temperature at the end of this century (208I-2100) relative to the recent past (1986-2005) for the lower (left) RCP2.6 and higher (right) RCP8.5 scenarios. (bottom) As in (top), but for maximum daily surface air temperature. minimum temperature extreme values are projected to occur half as often in the southern states and about five times less often in the northern states. Under the RCP8.5 scenario, these minimum extreme values are not projected to recur over most of the continent.

Generally the bias in CMIP5 temperature extremes compared to observations follow similar errors to the corresponding seasonal mean. For warm extremes in Fig. 3, the CMIP5 models are $2^{\circ}-5^{\circ} \mathrm{C}$ too high in the east half of the U.S. for return values calculated from 1986 to 2005 but lower than $2^{\circ} \mathrm{C}$ in the western half. For the cold extremes, the CMIP5 models are slightly more than $2^{\circ} \mathrm{C}$ colder than observed in the western half of the U.S. and less and $2^{\circ} \mathrm{C}$ colder than observed in the eastern half (Kharin et al. 2013). Multimodel differences in reproducing 1986-2005 observed temperature return values over land areas are slightly larger than the differences in reproducing observed mean seasonal 
FIG. 4. Temporal decay of yearly frequency of recordbreaking monthly-mean temperatures aggregated over the U.S. $\left(30^{\circ}-50^{\circ} \mathrm{N}, 120^{\circ}-70^{\circ} \mathrm{W}\right)$. (top) Observed data from the Climatic Research Unit (CRU) database (Met Office, www.cru.uea.ac.uk/cru/data/temperature/), (middle) the model ensemble mean of $\mathbf{2 5}$ models totaling 100 members for the historical run, and (bottom) model ensemble mean of 22 models totaling 57 members for scenario RCP4.5. For an independently and identically distributed (iid) time series, in the first year (195I for observation and 2006 for scenario) every month is a record high and low (frequency is 12 ). In the second year, the chance of record breaking is reduced by half (6), and so on. As the number of years $n$ increases, it becomes harder to break a record; the record frequency diminishes according the $\mathrm{I} / \mathrm{n}$ rate (Meehl et al. 2009). By year 50, the probability is 0.24 $(0.02 \times 12)$ month $\mathrm{yr}^{-1}$ (black curve). Almost all record highs (red dots) fall below the statistically expected I/n value during $1955-75$ and are largely above the I/n curve afterward. The solid black curve represents the theoretically expected I/n curve (for an iid sequence) and the dashed red curve is I/n curve but with warming trend effect on the frequency. The red dots and blue asterisks are the model-simulated frequencies of high and low record temperatures, respectively.

temperatures with an average multimodel standard deviation of about $5^{\circ} \mathrm{C}$ (Kharin et al. 2013).

The frequency of record-breaking high or low monthly temperatures is another measure of extreme temperature change (Meehl et al. 2009). Figure 4 compares the frequency of high and low record monthly temperatures over a 50 -yr period averaged over U.S. During the 1990s the high record frequency was about 0.5 month $\mathrm{yr}^{-1}$, roughly double that expected in an unchanging climate (top panel). An increase in mean temperature itself increases the chance of breaking a record high temperature by about $50 \%$, as reflected by the red dashed curve (Wergen and Krug 2010). Similarly, minimum temperature records were overwhelmingly lower than would be expected in an unchanging climate (about 0.12), producing a high/ low record-breaking temperature ratio of 4 during the last $10 \mathrm{yr}-\mathrm{a}$ ratio that should be equal to 1 in an unchanging climate. The historical runs capture the general decay trend in record frequency, but the high (low) temperature records recur slightly less (more) frequently than observed during mid-1980s to mid1990s (middle panel).

Projections using the mid-low RCP4.5 scenario show that the high (low) monthly record temperatures would occur much more (less) frequently in the future (bottom panel) with respect to the 50-yr time frame starting in 2006. By the middle of the century under mid-low emissions (RCP4.5), record high

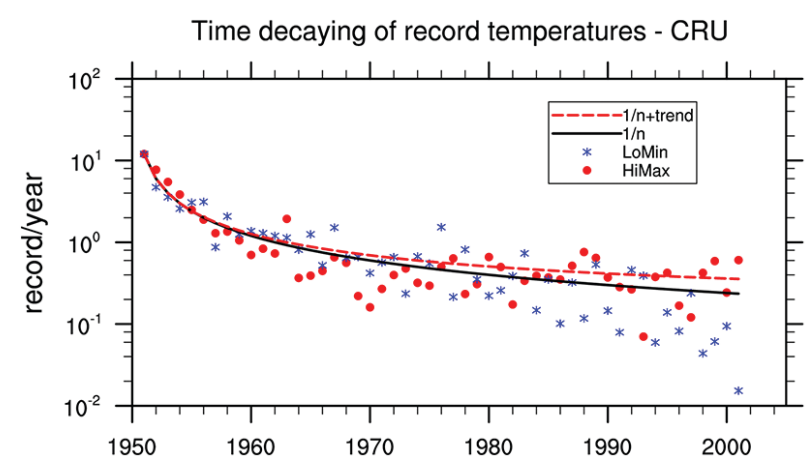

Time decaying of record temperatures - His

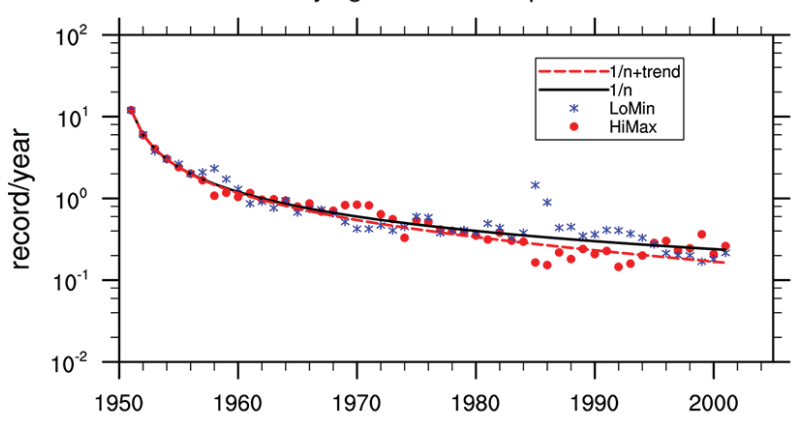

Time decaying of record temperatures - RCP

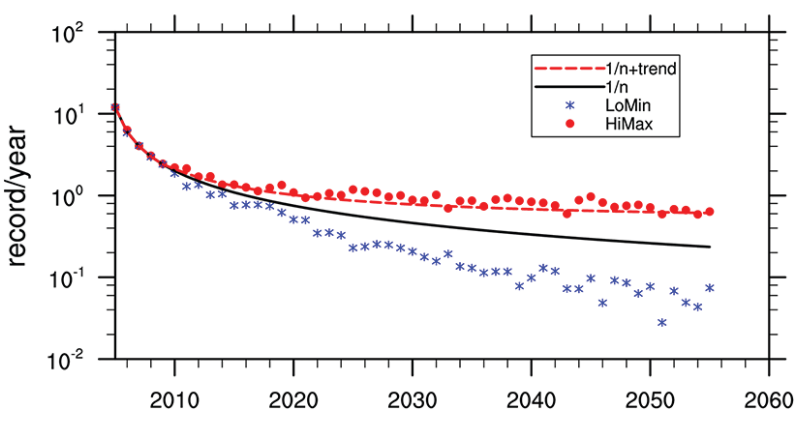

temperatures are projected to be broken at a rate of 0.9 months $\mathrm{yr}^{-1}$ and record low temperatures at a rate of 0.07 months $\mathrm{yr}^{-1}$, which gives a high/low temperature record ratio greater than 10 (a value achieved for daily records in July 2012, during the worst U.S. drought in the past five decades). This large ratio cannot be entirely explained by the increase in mean temperature; rather, it suggests a change in the shape of the tails of the daily temperature distribution, consistent with other studies of extreme temperature (Wehner 2005).

EXTREME PRECIPITATION. The extreme precipitation index (EPI; Kunkel et al. 1999, 2003, 2007) has been previously used to provide strong evidence for an upward trend in the frequency and intensity of extreme precipitation events in the U.S. (e.g., Kunkel et al. 2013). Figure 5 (top) compares EPI decadal anomalies based on CMIP5 models to observations for 2-day duration 1-in-5-yr events over the CONUS. 
The EPI was calculated annually from 1901 to 2005, and then decadal averages were calculated for the period 1906-2005.

A positive trend in EPI anomalies is evident from observations over the past 4 decades. The multimodel median of CMIP5 simulations also shows an increasing trend in EPI anomalies over the same time period, albeit smaller than observed. The standard deviation between the models is extremely large, often greater than the signal, indicating that there are large differences between extreme precipitation events in the models (see Fig. ES2 in the supplementary materials, which compares the

EPI Percent Anomaly Observations and Historical Simulations - CONUS
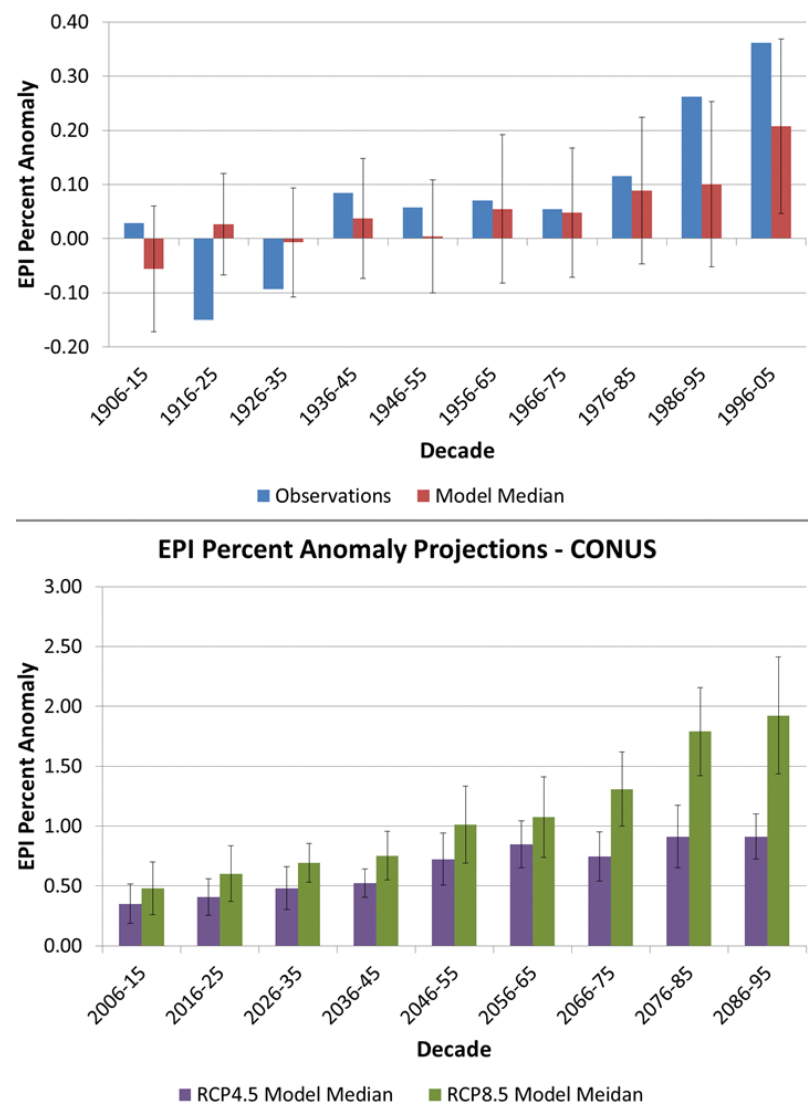

Fig. 5. (top) Observed decadal (blue) and modeled (red) EPI percent anomalies for 2-day duration and I-in-5-yr events: percent deviation from the long-term mean $(1901-60)$. The red bars are the median of the CMIP5 historical simulations from 1906 to 2005. The error bars represent \pm I standard deviation of the models. (bottom) The model median of EPI percent anomalies for RCP4.5 (purple) and RCP8.5 (green) and historical model simulations for the period $190 \mathrm{I}-2100$ by decade. The long-term mean is $190 \mid-60$. Error bars show the spread of the models as \pm I standard deviation. correlation coefficient of observed and modeled decadal average EPI values for the CONUS for each of the 26 CMIP5 models used). Many models have a correlation coefficient with observations greater than 0.50, with the Beijing Climate Center, Climate System Model, version 1.1 (BCC_CSM1.1), for example, approaching 1.00 for a 10 -yr return. At the same time, however, seven of the models have a negative correlation, demonstrating the large spread in model ability to capture observed trends in extreme precipitation events. In terms of future projections, Fig. 5 (bottom) shows an increasing trend in EPI values under both the mid-low RCP4.5 and the higher RCP8.5 scenarios. For these projections, the multimodel spread is smaller than the signal, indicating strong agreement of an increase in the EPI across all models. Figure ES3 in the supplementary materials shows that there is a large variation between ensemble individual runs.

An alternate indicator of long-term trends in extreme precipitation is the fraction of the annual total precipitation that falls in the heaviest $1 \%$ of daily events. Figure 6 compares simulated historical changes in the top $1 \%$ of extreme CONUS precipitation over time with observed data, calculating the 99th percentile for the base period (1900-60), ignoring all days with less than $1 \mathrm{~mm}$ of precipitation at each grid point, and summing the data for days above that threshold. The models show an increase

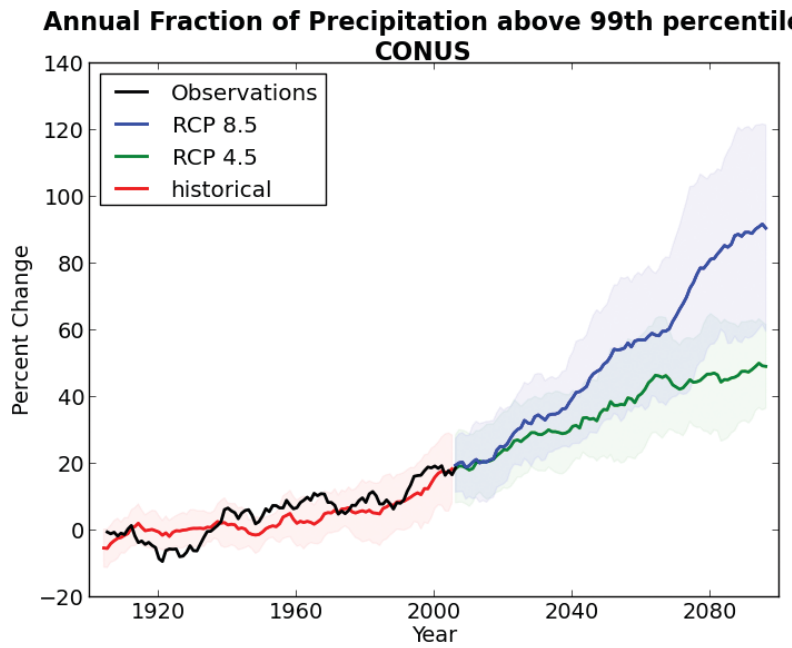

FIG. 6. Percentage of annual precipitation over the contiguous U.S. falling in the heaviest I\% of daily precipitation events, relative to the $1901-60$ average, as simulated by the CMIP5 historical simulations (1900-2005) and the RCP4.5 and RCP8.5 simulations (2006-2100). Observational data (190I-2010) are also shown. The solid lines and shaded areas represent the mean and standard deviation of the 9-yr running average. 
in the amount of precipitation falling in the largest $1 \%$ of events throughout the last century (19012000). CMIP5 historical changes in heavy precipitation are broadly consistent with changes in observed heavy precipitation from 1958 to 2007 (Karl et al. 2009). By the end of this century, a $50 \%$ increase in the annual fraction of precipitation falling in the heaviest events is projected for the mid-low scenario (RCP4.5), while a $90 \%$ increase is projected for the higher scenario (RCP8.5). In general, CMIP5 results suggest that a greater percentage of annual precipitation will fall in the top $1 \%$ of events over time and are consistent with the conclusions reached in similar analyses of CMIP3 models (Wehner 2005).

Long period return values represent much rarer extremes than the 99th percentile. Figure 7 (upper) shows that the CMIP5 projection of percent changes in the 20 -yr return value of the annual maximum daily precipitation at the end of this century (20812100) relative to the recent past (1986-2005) under the higher and lower RCP scenarios increases everywhere in CONUS and Alaska (Kharin et al. 2013). Such rare precipitation events have been increasing (Kunkel et al. 2003; Min et al. 2011; Field et al. 2012) and are also projected to occur more frequently in the future (Fig. 7, lower) but not as often as for warm temperature events of the same current frequency. At the end of this century under the higher RCP8.5 scenario, the current 20-yr event is projected to occur about twice as often in the interior of the U.S., about 3-4 times more frequently along the coasts, and up to 7 times more frequently in parts of Alaska than it does now.

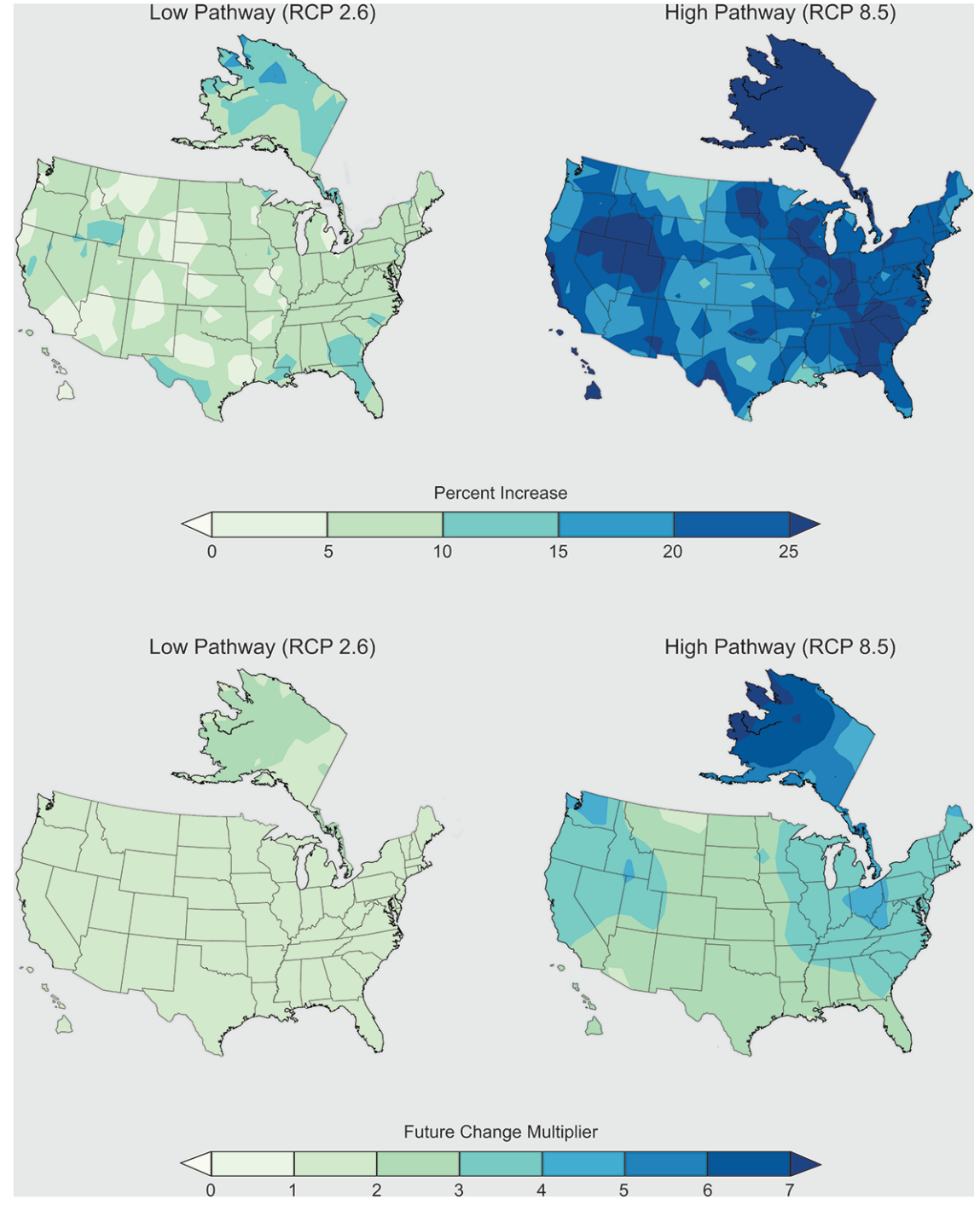

FIG. 7. (top) Projected change (\%) in the 20 -yr return value of annual maximum daily precipitation at the end of this century $(2081-2100)$ relative to the recent past (1986-2005) for the lower (left) RCP2.6 and higher (right) RCP8.5 scenarios. (bottom) The relative rate at which the 1986-2005 20-yr return value of annual maximum daily precipitation is projected to occur during 208I-2100. A value of two would mean that such an extreme event happens twice as often.

\section{LARGE-SCALE DRIVERS OF PRECIPITA-} TION VARIABILITY AND DROUGHT.

Drought has been a constant challenge for the U.S. Southwest and, in recent years, for the Southeast as well. A sizeable fraction of the precipitation in the arid Southwest derives from the North American monsoon. Past studies using CMIP3 models (e.g., Liang et al. 2008) have shown that climate models do not simulate all aspects of the circulation patterns associated with the monsoon well. The CMIP5 models' simulation of the seasonal cycle of precipitation (Cook and Seager 2013) appears improved over 


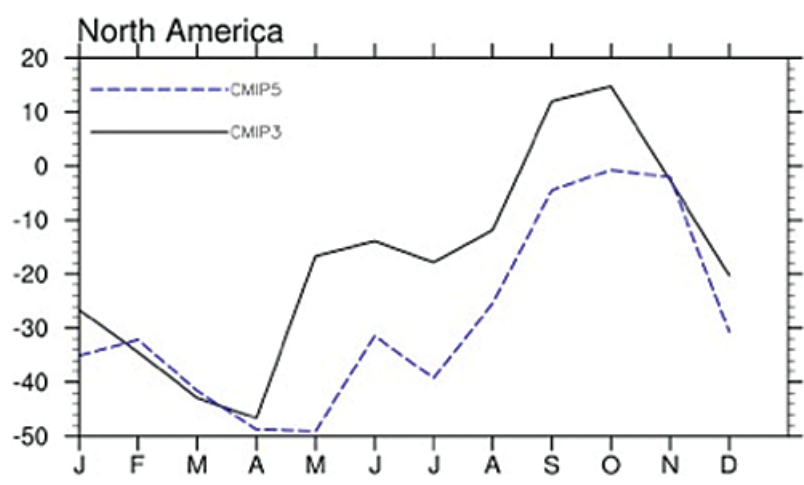

FIG. 8. Percent change in multimodel ensemblemean monthly precipitation for the North American monsoon region $\left(29^{\circ}-35^{\circ} \mathrm{N}, 112.5^{\circ}-120^{\circ} \mathrm{W}\right)$ for CMIP3 (207I-2100 SRES mid-high A2 minus 197I-2000 20C3m, and CMIP5 (2076-2100 higher RCP8.5 minus |98|-2005 historical).

CMIP3 (Liang et al. 2008). Observations indicate a decrease in monsoon rainfall over the past two decades, which may partially result from anthropogenically forced warming (Arias et al. 2012). CMIP3 analyses of changes in the annual cycle of precipitation in the North American monsoon region suggested reductions during winter and early summer rainy seasons but indicate increased rainfall later in the rainy season (Seth et al. 2011). CMIP5 simulations (Fig. 8) show a similar response but a stronger reduction in precipitation in the winter and spring, possibly owing to the stronger radiative forcing in the RCP8.5 versus the SRES A2 scenario (also see Seth et al. 2013). A 1979-2005 historical comparison indicates CMIP5 models are drier (by 2-4 $\mathrm{mm} \mathrm{day}^{-1}$ ) than observed through March-September in the core monsoon region, south of $20^{\circ} \mathrm{N}$, and slightly wetter (0.5-2 $\left.\mathrm{mm} \mathrm{day}^{-1}\right)$ than observed from May to September from $20^{\circ}$ to $25^{\circ} \mathrm{N}$ (Sheffield et al. 2013).

In the Southeast, the seasonal cycle of precipitation is strongly influenced by the position of the western ridge of the North Atlantic subtropical high (NASH). Comparing historical simulated and observed year-to-year variations in summer [June-August (JJA)] precipitation in the Southeast U.S. identified a subgroup of the CMIP5 models that simulate the summer precipitation variability reasonably well owing to their proper representation of the link with the western ridge position. In this subgroup of models, future variability intensifies under the mid-low RCP4.5 scenario due to a pattern shift of the NASH western ridge. The NASH western ridge extends farther westward and leads to more frequent occurrences of both the northwestward and southwestward ridge patterns that are respectively related to the dry and wet Southeast U.S. summers-in other words, increasing interannual variability (Li et al. 2011, 2013).

At the global scale, previous evaluations of CMIP3 twenty-first-century projections (Sheffield and Wood 2008) indicated general decreases in soil moisture and a corresponding increase in drought frequency, duration, area, and severity with increasing temperature. CMIP5 models show similar twenty-first-century decreases in soil moisture in most global land areas in summer. There has been a recent increase in the frequency of severe to extreme drought in the western U.S., and the CMIP5 models simulate such an increase for the early twenty-first century (Fig. 9). There is consensus among the models for future summer soil moisture decreases throughout the U.S.. and for winter soil moisture decreases in most of the CONUS (Dirmeyer et al. 2013). Comparisons of CMIP3 and CMIP5 twentieth-century simulations against offline hydrological modeling estimates of global drought variability (Sheffield and Wood 2007) indicate that the models on average capture the regional variation in drought frequency, although there are large intermodel variations and a tendency to overestimate longer-term drought frequency (Fig. 9). The latter is related to differences in modeled variability at interannual to decadal time scales and differing land surface representations.

The south-central U.S. has been prone to drought and floods historically and experienced its worst single year drought in 2011. By the late twenty-first century (2073-99), the CMIP5 models ensemblemean projections suggest that the net surface water gain over this region, defined as the precipitation minus evapotranspiration $(P-\mathrm{ET})$, will decrease significantly during winter, spring, and fall significantly $\left(\sim 0.2 \mathrm{~mm} \mathrm{day}^{-1}\right.$ or $\left.20 \%\right)$ under the RCP8.5 scenario relative to that of 1979-2005. Such changes are mainly due to a stronger increase of ET during these seasons, which more than negates a small increase of rainfall during spring. Because soil moisture is recharged during winter and spring in the current climate (1979-2005), the projected reduction of net surface water gain in these seasons would reduce soil moisture and increase the risk of droughts.

EXTRATROPICAL STORMS. Future changes in extratropical cyclones could affect the risk and severity of extreme precipitation over the CONUS, particularly along the eastern seaboard. Recent observational studies have documented a decrease in the frequency of warm season extratropical cyclones over the northeastern U.S. (Leibensperger et al. 2008), 
while other studies have shown a future decrease in cyclone frequency over the western Atlantic storm track using CMIP3 and other models (Lambert and Fyfe 2006; Bengtsson et al. 2006). Colle et al. (2013) present a more detailed summary of past studies investigating future cyclone changes for this region. Our analysis focuses on eastern North America during the cool season (November-March) using the Hodges $(1994,1995)$ cyclone tracking scheme to track the cyclones in 15 CMIP5 models (see supplement) using 6-h mean sea level pressure data. Colle et al. (2013) describes the tracking approach and some validation of the tracking procedure for the historical 1979-2004 period during the cool season. They also rank the models and show that six out of the seven top-performing models are the higher-resolution CMIP5 models.

Figure 10a shows the change in cyclone track density over eastern North America and much of the northern Atlantic between the 2039 and 2068 cool seasons and the historical (1979-2004) period, and dotted locations highlight where at least $73 \%$ (11 of the 15) of the models predict the same sign of the cyclone changes. Projected changes in cyclone tracks and cyclone deepening, or strengthening, vary substantially from one region to the next. For example, cyclone density is projected to decrease over the western Atlantic but change little or slightly increase over northern New England. Over the smaller U.S. East Coast region, relatively weak cyclones are projected to decrease while stronger cyclones $(<980 \mathrm{hPa})$ are projected to increase (Fig. 10c); however, there is a relatively large standard deviation in the future change of deep cyclones, ranging from a near doubling to no change. Colle et al. (2013) highlights a statistically significant upward trend in the number of relatively strong cyclones along the U.S. East Coast through the mid-twenty-first century using the "best seven" CMIP5 models. In contrast, for the larger Atlantic domain there is a $3 \%-9 \%$ projected reduction in
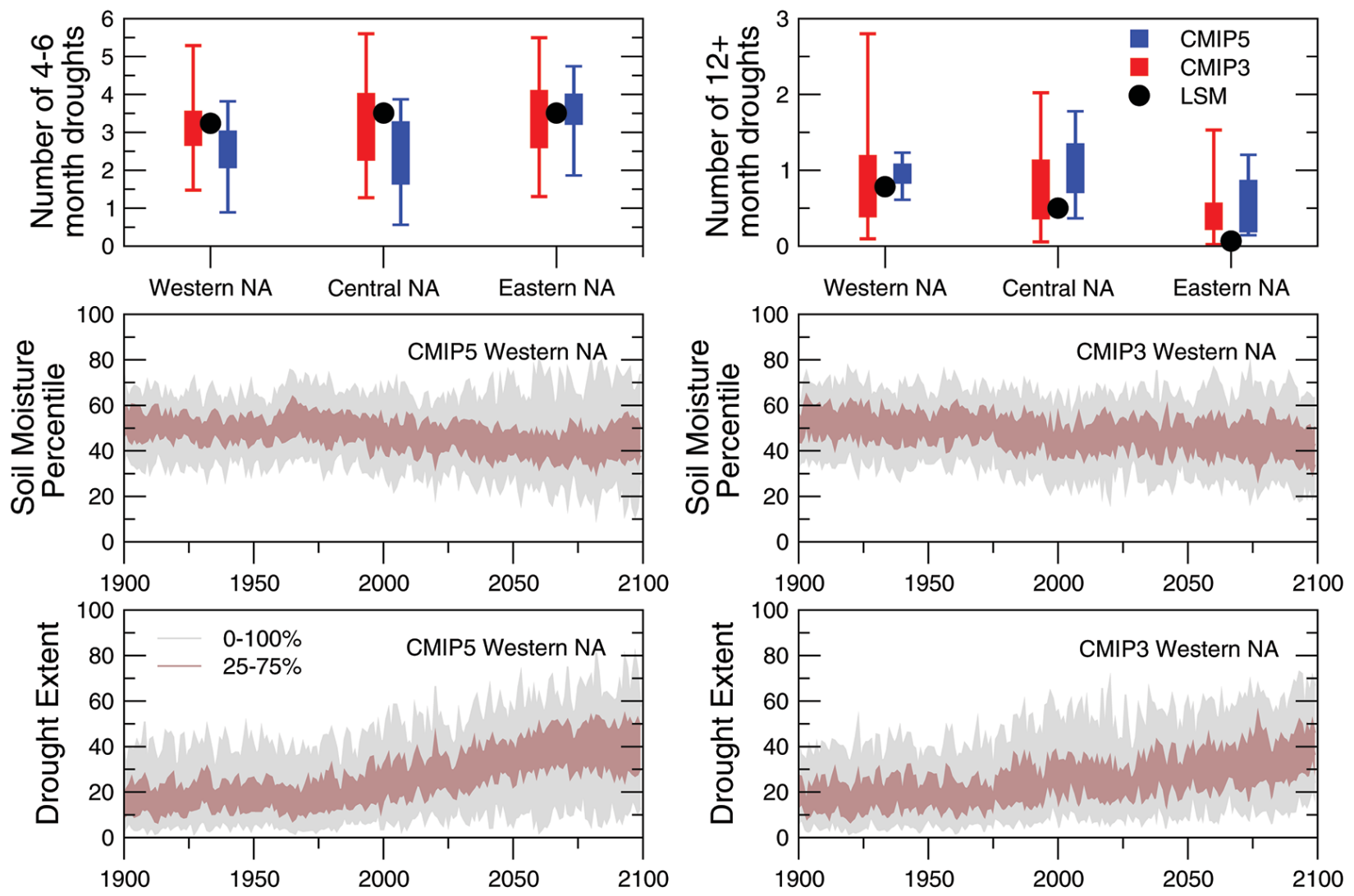

FIG. 9. (top) Evaluation of CMIP5 and CMIP3 models against offline land surface model (LSM) estimates of observed regional drought frequency (number of droughts per $30 \mathrm{yr}$ ) for (left) droughts that last for 4-6 months and (right) droughts that last for more than 12 months. (middle) Distribution of projected changes in soil moisture percentile from (left) CMIP5 and (right) CMIP3 models for western North America. (bottom) Distribution of projected changes in drought extent from (left) CMIP5 (higher RCP8.5 scenario) and (right) CMIP3 (mid-high SRES A2 scenario) models for western North America. Drought is defined as soil moisture below the 20 th percentile. 
the number of relatively strong cyclones (Colle et al. 2013).

The rate at which cyclones strengthen, or deepen, is also projected to change. Over the Northeast, there is a $10 \%-30 \%$ mean increase in the number of CMIP 5 cyclones deepening by more than $5 \mathrm{hPa}$ in $6 \mathrm{~h}$ (Fig. 10d), with a relatively large spread from a $40 \%$ to $60 \%$ decrease to a $60 \%$ to $90 \%$ increase. Meanwhile, the mean CMIP5 weakening rates of more than $2 \mathrm{hPa}$ in $6 \mathrm{~h}$ decrease by $\sim 5 \%$, but there is a relatively large uncertainty in this weakening. Just offshore of the U.S. East Coast deepening rates are projected to decrease by $10 \%-20 \%$ by the midtwenty-first century (Fig. 10b). By the late twentyfirst century, a widespread $10 \%-30 \%$ decrease in

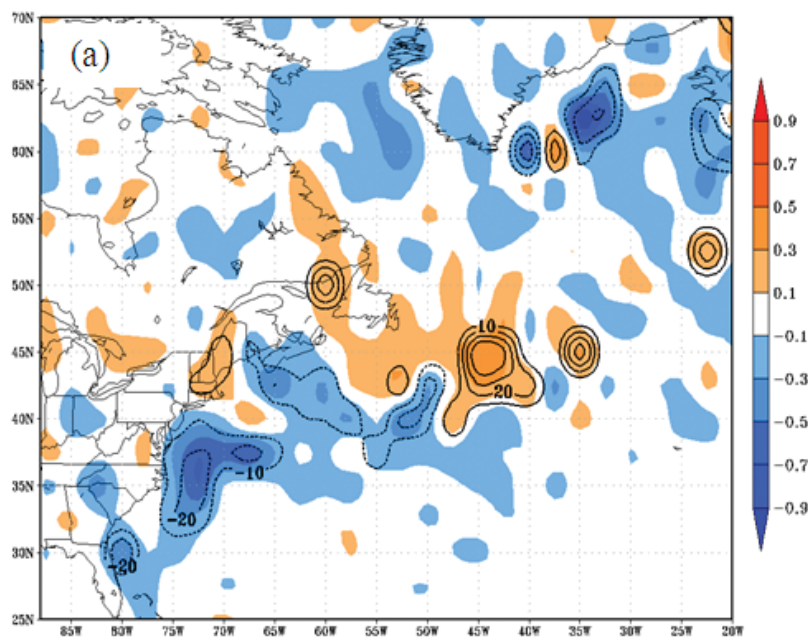

(c)

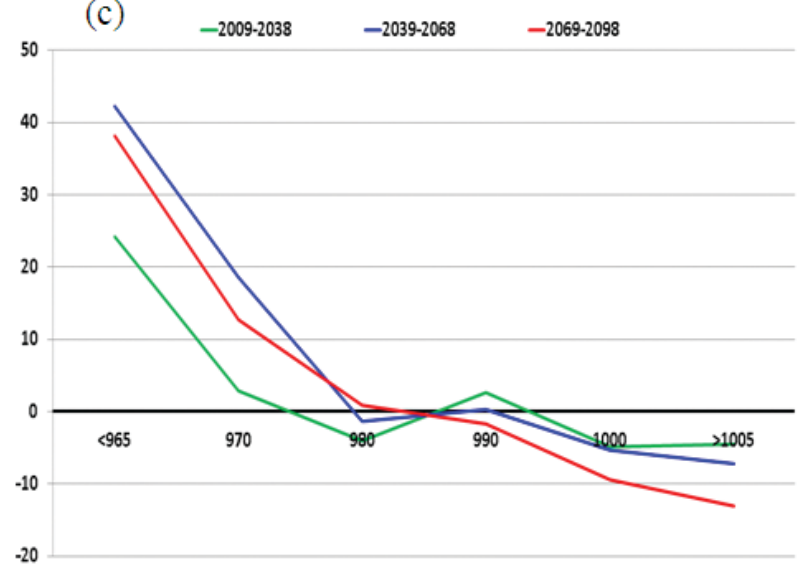

$5 \mathrm{hPa}$ per 6-h deepening is projected over much of the western and northern Atlantic (not shown). Colle et al. (2013) provide some evidence to suggest this more rapid deepening is the result of increased latent heating. Overall, these results highlight the enormous complexity of projecting the impacts of global change on regional dynamics and storm systems. Additional research is needed using higherresolution regional models, but overall these CMIP5 results suggest that increasing cyclone intensity may lead to more wind and heavy precipitation extremes along the U.S. East Coast.

SUMMARY. This paper summarizes the results of a series of analyses based on the CMIP5 models

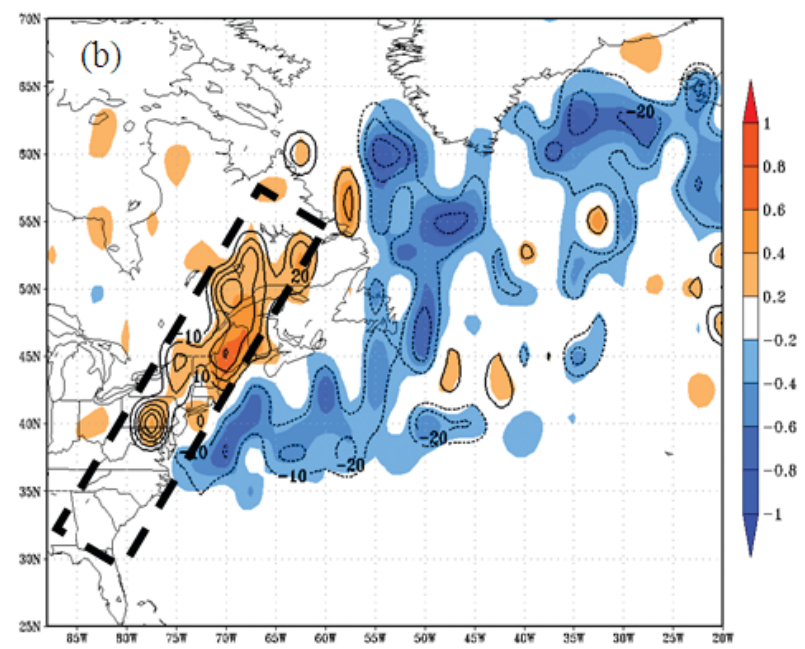

(d)

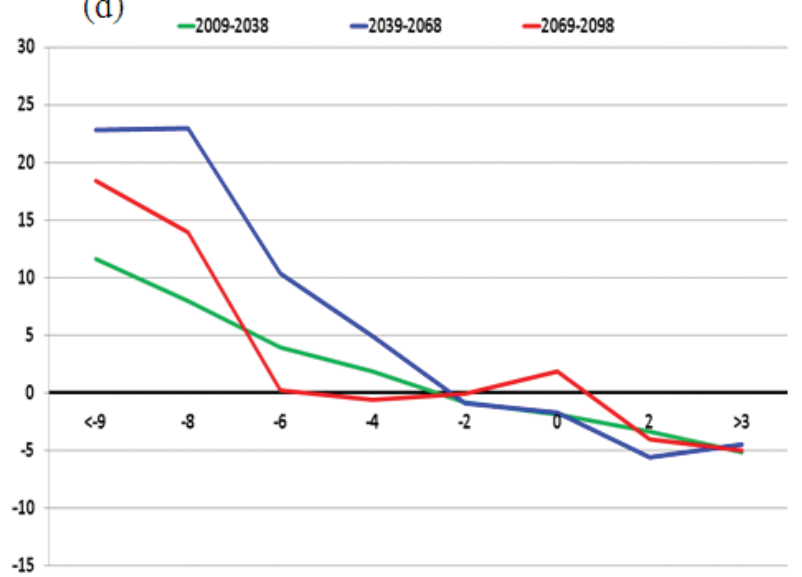

Fig. 10. (a) Difference in cyclone track density per $50,000 \mathrm{~km}^{2}$ (shaded every 0.2 ) and the percent change (contoured every 10\%) for the mean of 15 CMIP members between the cool seasons of 2039-68 and the historical (1979-2004) period. (b) As in (a), but for the change in the number of 6-h cyclone deepening rates $>5 \mathrm{hPa}$ (shaded as the number of cyclone tracks per 5 cool seasons per $50,000 \mathrm{~km}^{2}$ ) and the percentage change (contoured every $10 \%$ with negative dashed). (c) Percentage difference in the number of cyclone central pressures centered for each $10-\mathrm{hPa}$ bin over the dashed box in (b) between each of the three future periods and 1979-2004 cool seasons. (d) As in (c), but for 6-h deepening rate in $\mathrm{hPa}$, which includes the full evolution of all cyclones within the box in (b). 
examining changes in temperature extremes, precipitation extremes, droughts, and atmospheric patterns such as the North American monsoon and the North Atlantic subtropical high that affect extreme temperatures, interannual precipitation, and extratropical cyclones over the continental U.S. Based on these analyses, including the comparison of the new CMIP5 model experiments with older CMIP3 projections and, where possible, with historical observed trends, we find the following:

- Despite higher model resolution and increased complexity, the spatial patterns, direction of change, and overall magnitudes of projected changes in mean and extreme temperature and precipitation do not differ substantially from CMIP3 to CMIP5, particularly when differences in forcings are accounted for.

- Historical observations, model simulations, and future projections consistently show increases in the frequency of high temperature extremes and decreases in low temperature extremes across different indicators that cover a broad range of return periods, quantiles, or record-breaking frequencies.

- Observations, historical simulations, and future projections also agree on increases in heavy precipitation events consistent across a range of indicators. However, there are large differences between model simulations in the rate of heavy precipitation increase, with many tending to underestimate the historical observed trend. Models do project a further increasing trend in severe precipitation events in the future.

- Projected changes in drought risk based on soil moisture show consistent increases in both summer and winter seasons across the U.S. as a whole. Model ability to simulate large-scale dynamical features such as the North American monsoon (for the Southwest) and the North Atlantic subtropical high (for the Southeast) is critical to simulating trends in long-term summer drought risk for those regions and CMIP5 models vary in the accuracy of their simulations of these features

- Although extratropical cyclones may become weaker and less frequent over much of the western Atlantic storm track, they may become more intense and deepen more rapidly just inland of the U.S. East Coast, especially by the middle of the twenty-first century. The CMIP5 analyses suggest that increasing cyclone intensity may lead to more wind and heavy precipitation extremes along the U.S. East Coast.
The studies presented in this paper provide preliminary analyses of CMIP5 and the comparison with historical trends and with CMIP3 results for extreme events. We believe this is a useful first look at how our confidence in the patterns and direction of change for extreme events has solidified as better and higherresolution models have become available, particularly as these new model simulations continue to paint the same broad-scale picture of increasing trends in high temperature and precipitation extremes found in earlier studies.

ACKNOWLEDGMENTS. This work was supported in part by NASA Award NNX12AF32G (University of Illinois), from the Regional and Global Climate Modeling Program and the Earth System Modeling Program of the Office of Biological and Environmental Research in the Department of Energy Office of Science under Contract DE-AC02-05CH11231 (LBL), from NSF Grant AGS1147608 (Duke), and by NOAA Award NA11OAR4310097 (Princeton University). We also acknowledge the support of NOAA Climate Program Office Modeling, Analysis, Predictions and Projections (MAPP) Program as part of the CMIP5 Task Force under Grant NA11OAR4310104 (Stony Brook) and NOAA NESDIS through the Cooperative Institute for Climate and Satellites-North Carolina under Cooperative Agreement NA09NES4400006.

\section{REFERENCES}

Andrews, T., J. M. Gregory, M. J. Webb, and K. E. Taylor, 2012: Forcing, feedbacks and climate sensitivity in CMIP5 coupled atmosphere-ocean climate models. Geophys. Res. Lett., 39, L09712, doi:10.1029/2012GL051607.

Arias, P. A., R. Fu, and K. C. Mo, 2012: Decadal variation of rainfall seasonality in the North American monsoon region and its potential causes. J. Climate, 25, 4258-4274.

Bengtsson, L., K. I. Hodges, and E. Roeckner, 2006: Storm tracks and climate change. J. Climate, 19, 3518-3543.

Colle, B. A., Z. Zhang, K. Lombardo, E. Chang, P. Liu, and M. Zhang, 2013: Historical evaluation and future prediction of eastern North America and western Atlantic extratropical cyclones in the CMIP5 models during the cool season. J. Climate, 26, 6882-6903.

Cook, B. I., and R. Seager, 2013: The response of the North American monsoon to increased greenhouse gas forcing. J. Geophys. Res., 118, 1690-1699, doi:10.1002/jgrd.50111.

Delworth, T. L., J. D. Mahlman, and T. R. Knutson, 1999: Changes in heat index associated with $\mathrm{CO}_{2}$-induced global warming. Climatic Change, 43, 369-386. 
Dirmeyer, P. A., Y. Jin, B. Singh, and Z. Yan, 2013: Trends in land-atmosphere interactions from CMIP5 simulations. J. Hydrometeor., 14, 829-849.

Field, C. B., and Coauthors, Eds., 2012: Managing the Risks of Extreme Events and Disasters to Advance Climate Change Adaptation. Cambridge University Press, 582 pp.

Fischer, E. M., and R. Knutti, 2013: Robust joint projections for humidity and temperature extremes. Nat. Climate Change, 3, 126-130, doi:10.1038 /nclimate1682.

—, K. W. Oleson, and D. M. Lawrence, 2012: Contrasting urban and rural heat stress responses to climate change. Geophys. Res. Lett., 39, L03705, doi:10.1029/2011GL050576.

Hibbard, K. A., G. A. Meehl, P. Cox, and P. Friedlingstein, 2007: A strategy for climate change stabilization experiments. Eos, Trans. Amer. Geophys. Union, 88, 217-221.

Hodges, K. I., 1994: A general method for tracking analysis and its application to meteorological data. Mon. Wea. Rev., 122, 2573-2586.

_ 1995: Feature tracking on the unit sphere. Mon. Wea. Rev., 123, 3458-3465.

Karl, T. R., J. M. Melillo, and T. C. Peterson, Eds., 2009: Global Climate Change Impacts in the United States. Cambridge University Press, 188 pp.

— , and Coauthors, 2012: U.S. temperature and drought: Recent anomalies and trends. Eos, Trans. Amer. Geophys. Union, 93, 473-474.

Kharin, V. V., F. W. Zwiers, X. Zhang, and M. Wehner, 2013: Changes in temperature and precipitation extremes in the CMIP5 ensemble. Climatic Change, 119, 345-357.

Knutti, R., and J. Sedláček, 2012: Robustness and uncertainties in the new CMIP5 climate model projections. Nat. Climate Change, 3, 369-373, doi:10.1038 /nclimate1716.

Kunkel, K. E., K. Andsager, and D. R. Easterling, 1999: Long-term trends in extreme precipitation events over the conterminous United States and Canada. J. Climate, 12, 2515-2527.

— , D. R. Easterling, K. Redmond, and K. Hubbard, 2003: Temporal variations of extreme precipitation events in the United States: 1895-2000. Geophys. Res. Lett., 30, 1900, doi:10.1029/2003GL018052.

_ , T. R. Karl, and D. R. Easterling, 2007: A Monte Carlo assessment of uncertainties in heavy precipitation frequency variations. J. Hydrometeor., 8 , 1152-1160, doi:10.1175/JHM632.1.

_ , and Coauthors, 2013: Monitoring and understanding trends in extreme storms: State of knowledge. Bull. Amer. Meteor. Soc., 94, 499-514.
Lambert, S. J., and J. C. Fyfe, 2006: Changes in winter cyclone frequencies and strengths simulated in enhanced greenhouse warming experiments: Results from the models participating in the IPCC diagnostic exercise. Climate Dyn., 26, 713-728.

Leibensperger, M. E., L. J. Mickley, and D. J. Jacob, 2008 : Sensitivity of U.S. air quality to mid-latitude cyclone frequency and implications of 1980-2006 climate change. Atmos. Chem. Phys., 8, 7075-7086.

Li, L., W. Li, and Y. Kushnir, 2011: Variation of North Atlantic subtropical high western ridge and its implications to the southeastern US summer precipitation. Climate Dyn., 39, 1401-1412, doi:10.1007 /s00382-011-1214-y.

— — _ and Y. Deng, 2013: Summer rainfall variability over the southeastern United States and its intensification in the 21st century as assessed by the CMIP5 models. J. Geophys. Res. Atmos., 118, 340-354, doi:10.1002/jgrd.50136.

Liang, X.-Z., J. Zhu, K. E. Kunkel, M. Ting, and J. X. L. Wang, 2008: Do CGCMs simulate the North American monsoon precipitation seasonal-interannual variations. J. Climate, 21, 3755-3775.

Masterson, J. M., and F. A. Richardson, 1979: HUMIDEX: A method of quantifying human discomfort due to excessive heat and humidity. Environment Canada Rep., 45 pp.

Meehl, G. A., and K. A. Hibbard, 2007: A strategy for climate change stabilization experiments with AOGCMs and ESMs. WCRP Informal Rep. 3/2007, ICPO Publ. 112, IGBP Rep. 57, 35 pp.

- C. Covey, B. McAvaney, M. Latif, and R. J. Stouffer, 2005: Overview of the Coupled Model Intercomparison Project. Bull. Amer. Meteor. Soc., 86, 89-93.

,-- T. T. L. Delworth, M. Latif, B. McAveney, J. F. B. Mitchell, R. J. Stouffer, and K. E. Taylor, 2007: The WCRP CMIP3 multimodel dataset: A new era in climate change research. Bull. Amer. Meteor. Soc., 88, 1383-1394.

— , C. Tebaldi, G. Walton, D. Easterling, and L. McDaniel, 2009: Relative increase of record high maximum temperatures compared to record low minimum temperatures in the U.S. Geophys. Res. Lett., 36, L23701, doi:10.1029/2009GL040736.

Min, S.-K., X. Zhang, F. W. Zwiers, and G. C. Hergerl, 2011: Human contribution to more-intense precipitation extremes. Nature, 470, 378-381, doi:10.1038 /nature09763.

Moss, R. H., and Coauthors, 2010: The next generation of scenarios for climate change research and assessment. Nature, 463, 747-756, doi:10.1038 /nature08823. 
Nakicenovic, N., and R. Swart, Ed., 2000: Special Report on Emissions Scenarios. Cambridge University Press, $612 \mathrm{pp}$.

Peterson, T. C., and Coauthors, 2013: Monitoring and understanding changes in heat waves, cold waves, floods and droughts in the United States: State of knowledge. Bull. Amer. Meteor. Soc., 94, 821-834.

Seth, A., S. A. Rauscher, M. Rojas, S. Camargo, and A. Giannini, 2011: Enhanced spring convective barrier for monsoons in a warmer world? Climatic Change, 104, 403-414, doi:10.1007/s10584-010-9973-8.

—_ _ M. Biasutti, A. Giannini, S. Camargo, and M. Rojas, 2013: CMIP5 projected changes in the annual cycle of precipitation in monsoon regions. $J$. Climate, 26, 7328-7351.

Sheffield, J., and E. F. Wood, 2007: Characteristics of global and regional drought, 1950-2000: Analysis of soil moisture data from off-line simulation of the terrestrial hydrologic cycle. J. Geophys. Res., 112, D17115, doi:10.1029/2006JD008288.

— and — 2008: Projected changes in drought occurrence under future global warming from multi-model, multi-scenario, IPCC AR4 simulations. Climate Dyn., 13, 79-105, doi:10.1007/s00382-007-0340-z.

_- and Coauthors, 2013: North American climate in CMIP5 experiments. Part I: Evaluation of historical simulations of continental and regional climatology.

J. Climate, 26, 9209-9245.
Sherwood, S. C., and M. Huber, 2010: An adaptability limit to climate change due to heat stress. Proc. Natl. Acad. Sci. USA, 107, 9552-9555, doi:10.1073 /pnas.0913352107.

Steadman, R. G., 1979: The assessment of sultriness. Part I: A temperature-humidity index based on human physiology and clothing science. J. Appl. Meteor., 18, 861-873.

Taylor, K. E., R. J. Stouffer, and G. A. Meehl, 2012: The CMIP5 experiment design. Bull. Amer. Meteor. Soc., 93, 485-498.

van Vuuren, D. P., and Coauthors, 2011: The representative concentration pathways: An overview. Climatic Change, 109, 5-31, doi:10.1007/s10584-011-0148-z.

Vose, R. S., and Coauthors, 2014: Monitoring and understanding changes in extremes: Extratropical storms, winds, and waves. Bull. Amer. Meteor. Soc., 95, 377-386.

Wehner, M., 2005: Changes in daily precipitation and surface air temperature extremes in the IPCC AR4 models. U.S. CLIVAR Var., 3, 5-9.

Wergen, Q., and J. Krug, 2010: Record-breaking temperatures reveal a warming climate. Europhys. Lett., 92, 30008, doi:10.1209/0295-5075/92/30008.

Willett, K. M., and S. Sherwood, 2012: Exceedance of heat index thresholds for 15 regions under a warming climate using the wet-bulb globe temperature. Int. J. Climatol., 32, 161-177, doi:10.1002/joc.2257.

\section{CLIMATE CHANGE/POLICY}

“ This book is timely because global climate change policy is a mess.... Drawing on concrete examples and a broad range of social science theory, this book convincingly makes the case for a social learning approach to both adaptation and emissions mitigation."

- Steve Rayner, James Martin Professor of Science and Civilization, University of Oxford

\section{Adaptive Governance and Climate Change \\ RONALD D. BRUNNER AND AMANDA H. LYNCH}

As greenhouse gas emissions and temperatures at the poles continue to rise, so do damages from extreme weather events affecting countless lives. Meanwhile, ambitious international efforts to cut emissions have proved to be politically ineffective or infeasible. There is hope, however, in adaptive governance-an approach that has succeeded in some communities and can be undertaken by others around the globe.

In this book:

- A political and historical analysis of climate change policy

- How adaptive governance works on the ground

- Why local, bottom-up approaches should complement global-scale negotiations

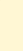

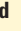
Governance Change

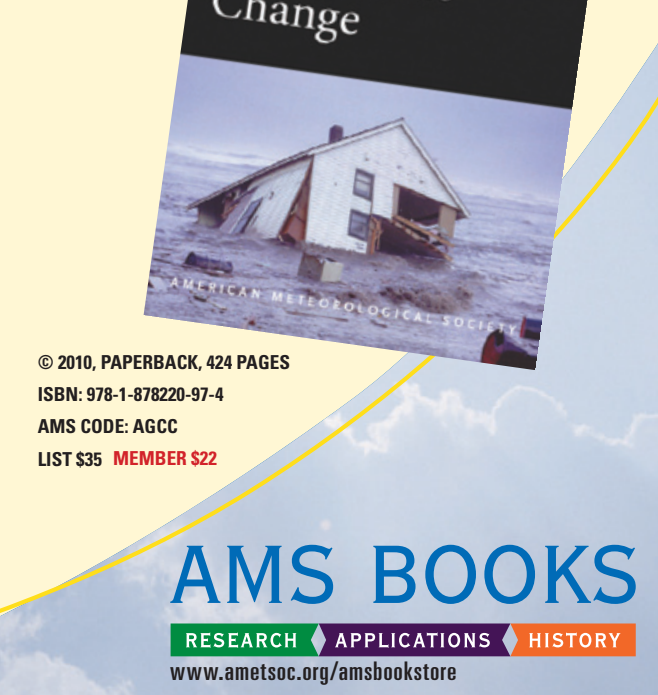




\section{Radar and Atmospheric Science: A Collection of Essays in Honor of David Atlas}

Edited by Roger M. Wakimoto and Ramesh Srivastava

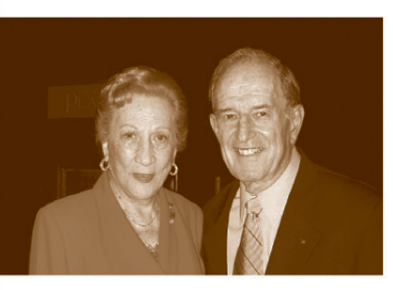

This monograph pays tribute to one of the leading scientists in meteorology, Dr. David Atlas. In addition to profiling the life and work of the acknowledged "Father of Radar Meteorology," this collection highlights many of the unique contributions he made to the understanding of the forcing and organization of convective systems, observation and modeling of atmospheric turbulence and waves, and cloud microphysical properties, among many other topics. It is hoped that this text will inspire the next generation of radar meteorologists, provide an excellent resource for scientists and educators, and serve as a historical record of the gathering of scholarly contributions honoring one of the most important meteorologists of our time.

Radar and Atmospheric Science:

\section{A Collection of Essays in Honor of David Atlas}

Aug 2003. Meteorological Monograph Series, Vol. 30, No. 52;

270 pp, hardbound; ISBN 1-878220-57-8; AMS code MM52.

Price $\$ 100.00$ list $/ \$ 80.00$ member

To place an order point your Web browser to www.ametsoc.org/amsbookstore 